\title{
Intercambio epistolar de León Tolstoi con América Latina
}

\begin{abstract}
Blas Nabel Pérez ${ }^{1}$
Resumen: El escritor ruso León Tolstoi dejó tras de sí un colosal testimonio de la época en que vivió, y mostró la energía del pueblo ruso durante el proceso de asentamiento de su identidad. Sostuvo un intercambio epistolar con sus seguidores en el mundo, conformado por más de 10000 cartas. Con celeridad asombrosa su obra fue conocida y querida en América Latina.
\end{abstract}

Palavras-chave: León Tolstoi; Literatura Russa

El escritor ruso León Tolstoi dejó tras de sí un colosal testimonio de una época de conflictos y contradicciones, de guerras, hambrunas y tormentos, y mostró la energía de un pueblo en el proceso de asentamiento de su identidad.

Sostuvo intercambio epistolar con centenares de sus seguidores en el mundo, cuyos testimonios se conservan en su archivo personal en la residencia de Yasnaya Poliana, situada a las afueras de Moscú. Solo 386 cartas de las más de 10000 que se conservan en su archivo han sido recogidas en 32 de los 90 tomos que conforman su obra completa. Con celeridad asombrosa, la obra de Tolstoi fue conocida y querida desde la Argentina a las Antillas. Un hecho explicable por la fisonomía de sus relatos y de sus prédicas.

El 16 de agosto de 1898, en su artículo "Dos Guerras”, daba a conocer desde Yasnaya Poliana su condena a la Guerra Hispano-americana. Planteaba Tolstoi: "En el mundo cristiano tienen lugar actualmente dos guerras. En verdad una prácticamente ha concluido, la otra no, pero ambas han sido simultáneas y el contraste entre ellas asombra. La que prácticamente ha concluido ha sido anticuada, dura, tonta y cruel, extemporánea, retrógrada, guerra entre paganos, la Hispano-americana ha servido para con la muerte de unos por otros decidir cómo y por quién deberán ser gobernados los terceros”.

Al referirse a la segunda guerra Tolstoi señalaba que la misma aún continuaba y sólo tendría fin cuando se acaben todas las guerras en el mundo, se refería a la Guerra Santa calificándola de inadmisible, brutal y feroz, señalaba: "La otra guerra, que aún continua y que tendrá fin cuando se terminen todas las guerras, es una nueva y abnegada, basada en el

\footnotetext{
${ }^{1}$ Filólogo(Universidad de la Habana), investigador y diplomático. Autor, entre otros libros, de: Armenios en el Nuevo Mundo, Las culturas que encontró Colón y Bibliografía del pintor ruso Vasily Vereschaguin en Cuba. Artículos suyos aparecen en revistas especializadas cubanas y extranjeras. Contacto: blasnabel@ hotmail.com
} 
amor y la razón - la guerra sagrada - la guerra contra la guerra, que ya hace tiempo - como ha expresado Víctor Hugo en uno de los Congresos - le ha declarado la parte mas avanzada de la humanidad cristiana a la otra parte brutal y salvaje de esa misma humanidad y que con especial fuerza y éxito lleva a cabo en el ultimo tiempo un puñado de hombres dispuestos a lograrlo - los cristianos - el clero del Cáucaso contra el poderoso Imperio Ruso".

"Por estos días, continuaba Tolstoi, recibí una carta de Colorado (EE. UU.) en la que un tal Sr. Dzhessi Golvdin me pedía que le enviase algunas palabras o reflexiones en la que expresara mis opiniones sobre la noble misión de la nación americana y el heroísmo de sus soldados y marinos." "Señor", planteaba Tolstoi en su respuesta, "estoy seguro en coincidir con la enorme mayoría del pueblo norteamericano, que la misión de los americanos consistió en matar a algunos miles de personas casi desarmadas. La Guerra Hispanoamericana, sin hablar de aquellos horrores que cometieron los españoles en Cuba y los cuales sirvieron de pretexto para desencadenar la propia guerra, se parece a lo siguiente: Un anciano que ha perdido razón y las fuerzas; y educado en reglas del falso honor convoca a un joven, que posee todas sus fuerzas, para solucionar las divergencias surgidas entre ambos mediante un pugilato. El joven, acepta el reto y según su propia versión de los hechos que ha contado en múltiples ocasiones, ataca al anciano, que estaba desquiciado y sin fuerzas, le rompe los dientes y las costillas y luego cuenta con alborozo sus hazañas a un enorme público integrado por jóvenes semejantes a él, los cuales se alegran y alaban al héroe".

Entre las cartas encontradas en el archivo de Tolstói son numerosas las enviadas desde la América Latina., algunas de ellas acompañadas de tarjetas postales. Es significativo que las de mayor contenido provienen de personas humildes que hacían frente a las condiciones de la realidad colonial que se vivía. Resalta también el hecho de que a pesar de tratarse de personas sencillas y con poca cultura, leyeran las obras de Tolstoi y lo reconocieran como un poderoso líder a quien seguir en sus ideas. Tolstói es, en lo dominante, el señor magnánimo, que se acerca a los pobres y el predicador de un evangelio de nuevas claridades.

Sobresalen las cartas enviadas por mujeres que le ruegan a Tolstoi les envíe su autógrafo. Todas van, como palomas ociosas, al mismo objetivo: que el Sr. Conde les envíe su autógrafo. Casi siempre se acompaña a la carta una tarjeta postal de paisaje con leyenda 
en inglés: Güines Road, El Viso Fort, El Cristo Station... Algunas cartas están escritas en español; otras en un francés de muy variable calidad, muchas en el típico inglés aprendido en los colegios de los Estados Unidos.

La más notable fue la de la joven Manuela Inda Rodríguez del poblado, de Guanajay, siete años antes de que falleciera el extraordinario escritor, como lo prueba una tarjetapostal que la muchacha le envió y la cual regresó a sus manos con la rúbrica de Tolstoi el 25 de octubre de 1903. El hecho fue consignado en un número de La Gaceta de Cuba.

Las cartas recibidas por Tolstoi provienen de dos fuentes: los más ricos y los más pobres. Entre las cartas del primer grupo un buen número son de mujeres pertenecientes a las familias de más rango y fortuna. Sus nombres lo señalan: Isabel Gárrate, Señoritas de Báez y Bolívar, Madame Louise Supervielle, María Teresa Demestre, Ophelia Kricghof Báez, Sophia Zorrilla.

Entre otras se descubre un rastro de orden intelectual como la misiva de Manuel García Garófalo Mesa y la carta de Enrique Gómez Carrillo, cónsul general de Guatemala en París, quien pide al novelista que colabore en un Álbum de Minerva, desde donde se fomentará, dice, el amor al estudio a través del dicho de los más altos maestros. Otra carta es del conocido político argentino Don Alfredo L. Palacios. El texto de la misiva nos muestra el varón honesto, altisonante y enfático; fechada en Buenos Aires el 19 de febrero de 1899 comienza así:

"A León Tolstói - Hermano: hace un lustro que os amo. Apenas tengo veinte años. Vos me habéis enseñado que los pobres tienen hambre porque los ricos comen mucho: y agrega: “¡Vos que lleváis pan al hambriento a su miserable cabaña, habéis llegado al trono vestido de mujic para aconsejar a un soberano!" Y pide al final de la carta encendida, que Tolstoi le envíe unas palabras para situarlas al frente de su tesis doctoral sobre la miseria y el delito.

Las cartas más interesantes son, desde luego, las de gentes del pueblo, las de los trabajadores que sufren y luchan entre las durezas de una realidad colonial. La caligrafía y la redacción reflejan instrucción muy escasa; pero merece atención que en medio de tanta penuria económica y cultural se leyera a Tolstoi y se le tuviese como líder revolucionario y como patriarca de gran poder y sabiduría. 
Tiene mucha sustancia la carta de un joven trabajador de Camajuaní, que confiesa su poca experiencia en las luchas sociales y ruega a Tolstoi que le mande un Reglamento Fundamental de lo que es el socialismo, redactado por él. "Creo, dice el joven villareño, que si usted se toma la molestia de mandar solo un pedazo de papel de muy chica dimensión tendrá un amigo más en esta tierra divina, en este destierro de riquezas".

Conmovedora es la misiva escrita por una mujer trabajadora de Jesús del Monte. La carta de la señora Amable, hermosa en su dramática sencillez, dice:

\section{Sr. León Tolstoi:}

Hace algún tiempo que he leído en un periódico de mi país (Cuba) que por haberle pedido consejo a Ud. el Sr. Carnegie de qué debiera hacer con su capital, Ud. le aconsejó diera algo a los pobres y como que yo soy una de las muchas personas bien pobres le he escrito a dicho Sr. confiando en que Dios le hará contestarme, pero este Sr. debe de recibir miles de cartas diarias con el mismo objeto, y naturalmente por muy piadoso que sea no es posible darle a todo el que pide y de tan lejos no se sabrá si es cierto o no que todos sean pobres. Yo le digo que puedo presentarme al Cónsul de su país en el mío para que sepa quién soy y acredite que verdaderamente soy la esposa de un mecánico que gana poco para sufragar las necesidades de él, mías, y 5 hijos, ahora bien Sr. como que sé que es Ud. piadoso le suplico por sus seres más queridos me dedique un momento y le escriba al Sr. Carnegie recomendando a la Sra. C. Amable de Jesús del Monte 129 (a) Habana. Esto será el colmo de mi ventura, puesto que él lo atenderá muchísimo a Ud. y por lo tanto algún auxilio me enviará, y yo los bendeciré a los dos. Como un recurso de salvación inspirada por lo desconocido hago esta carta pues antes trabajaba mucho para ayudar a mi esposo, hoy lo hago también pero penosamente porque me duelen los pulmones.

Su atenta S S S que le anticipa las gracias y desea salud.

C. Amable

Jesús del Monte 129 (a)

Habana

Julio 31 1909"

Más de una nota significativa debe señalarse en la carta, sin duda histórica, enviada por trabajadores presos en la Cárcel de La Habana. Por su comienzo puede deducirse que la comunicación con el novelista se inició antes de los hechos sangrientos: "El no haber 
contestado antes.; ha sido por efectos de la huelga que te anuncié en la anterior", dice el firmante; es decir que mientras la huelga se preparaba se pedía la orientación del lejano camarada.

Compañero León Tolstoi, Salud.

Compañero, recibí la tuya de fecha 20 de septiembre del próximo pasado año. Leída en el grupo_hizo un efecto inmejorable. Las preguntas que haces a S. Aguilar, no pueden ser contestadas hasta después de los hechos, porque sino correríamos un fracaso seguro.

El no haber contestado antes a la (5...) ha sido por efectos de la huelga que te anuncié en la anterior. Esta fue hermosa, respondieron al primer llamamiento casi espontáneamente todos los trabajadores de La Habana y poblaciones limítrofes a la misma, con decisión extrema. Y de no ser por la arbitrariedad del Gobierno y la intervención forzosa de los veteranos, se hubiera extendido a toda la isla y buena parte de la Florida pues ya contábase con todo.

El 24 de noviembre del pasado año, fue teatro La Habana de algunas refriegas entre el pueblo y la policía; hubo 5 muertos del pueblo y más de 150 fueron heridos, de estos solo 112 casos los conocen las Autoridades por haber llevado a la fuerza a los heridos a las Casas de Socorro. Unos 87 compañeros han sido detenidos; de los cuales 40 fueron puestos en libertad; de los otros, unos en el hospital y los demás en la Cárcel. Se está incoando un proceso con motivo de.la huelga a 40 individuos, las acusaciones que pesan sobre estos son las siguientes: sedición, maquinación para alterar el precio de las cosas. Insultos y atentado contra las autoridades. Entre los acusados se cuenta un Concejal y el Alcalde de la Ciudad. Los Compañeros S. A., J. P., C. y yo, guardamos prisión por las mismas causas. Esto y lo muy ocupado que he estado me impidieron contestar antes. A tiempo oportuno contestaré a la $45 \ldots 21,56$ y 10.

Salud y R. S.

\section{A. Juvenat}

Cárcel de la Habana,

Enero 25 de 1903.

En contestación a la primera carta, Tolstoi formula algunas preguntas a sus interlocutores habaneros, preguntas que no han podido ser satisfechas entre los desvelos y violencias del movimiento vencido. ¿Será posible encontrar algún día esas preguntas, cuyo sentido, en razón de las circunstancias, han de ser de tanto relieve? 
A las distancias asistidos de ese juez insobornable y esclarecedor que es el tiempo, vemos cruzarse en el subsuelo de los hechos no pocas líneas que los protagonistas no pueden identificar. Tiene relieve irónico que el gran narrador ruso mostrase adhesión a un grupo de cubanos víctimas de la nueva metrópolis, mientras, a poco trecho aconsejaba a los jóvenes latinoamericanos el acogimiento favorable de la invasión norteña.

En la casa de Yásnaya Poliana se dan dos hechos que explican mucho de la actitud descaminada: Tolstói se inclinaba con frecuencia ante el primitivo gramófono regalo de Edison, y al recibir, también en obsequio, la más reciente máquina de escribir, le asigna una habitación como huésped ilustre, a la que pone el nombre de Remington. Deslumbrado por las invenciones y avances técnicos y sin atención de la mano que iba a manejarlos, veía en ellos la desaparición de menesteres angustiosos; y nada más. También aquí el imaginador sobre el pensador, el espejo, no la realidad.

\section{Bibliografía:}

CARPENTIER, Alejo: "Significado de León Tolstoi para América Latina" (en ruso), Inostrannaya Literatura (Literatura

Extranjera), n. ${ }^{\circ} 11,1960$, p. 229.

MARINELLO, JUAN: "La correspondencia cubana de León Tolstoi” (en ruso), Latinskaya Amerika (América Latina), n. ${ }^{2}$, 1964, Págs. 54-57

TOLSTOI, LEÓN: "Dos Guerras", Obras completas (en ruso), Editorial Judozhestvennaya Literatura, Moscú, 1954, t. 31. Págs. $97-98$

TOLSTOI, LEÓN: "Epistolario”, Obras completas (en ruso), Editorial Judozhestvennaya Literatura, Moscú, 1954, t. 70 . 